\title{
Anomalous Origin of Left Coronary Artery from Main Pulmonary Artery (ALCAPA) Who Underwent Two Coronary System Repair with a Novel Technique
}

\author{
Chandrashekhar Ponde, Monika Jawanjal, Kaushal Pandey, Uday Gandhe \\ P.D. Hinduja National Hospital, Mahim, Mumbai, India \\ Email: drmonika257@gmail.com, ijpshekhar277@gmail.com, drmona257@gmail.com, \\ ckpshekhar@yahoo.co.in
}

Received 25 May 2014; revised 25 June 2014; accepted 25 July 2014

Copyright (C) 2014 by authors and Scientific Research Publishing Inc.

This work is licensed under the Creative Commons Attribution International License (CC BY). http://creativecommons.org/licenses/by/4.0/

(c) $\underset{\mathrm{EY}}{\text { (i) }}$ Open Access

\section{Abstract}

We report clinical, CT, invasive coronary angiography and intra-operative findings of a symptomatic elderly man with anomalous origin of left coronary artery from pulmonary artery (ALCAPA). ALCAPA is a rare syndrome with anomalous origin of left main coronary artery (LMCA) from main pulmonary artery (MPA). Survival into adulthood is rare and our case is probably the oldest survivor who has undergone two coronary system repairs for this anomaly. The unique features of our case include: 1) Absence of "q" wave myocardial infarction on ECG; 2) Absence of significant mitral regurgitation; 3) Demonstration of stress induced perfusion defects in nuclear imaging which as per our knowledge has been done for the first time in the literature; 4) A unique technique of closing anomalous LMCA origin by a pericardial patch, sutured on the internal aspect of MPA is the hallmark of this case.

\section{Keywords}

ALCAPA, CT Coronary Angiography, Invasive Angiography

\section{Introduction}

ALCAPA which was originally described by Brooks [1] is a very rare congenital defect which accounts for $0.5 \%$ of all the congenital heart defects [2]. Without treatment $90 \%$ of infants die within $1^{\text {st }}$ year of life [3]. Rare survival in adulthood is usually because of abundant intercoronary collaterals. The first clinical description along 
with autopsy findings was described by Bland and Colleagues and therefore called Bland White Garland (BWG) syndrome [4].

To our knowledge, this is the oldest patient who has undergone surgical repair for this anomaly.

\section{Case Presentation}

A 60 years old male with history of hypertension for last 6 years presented with typical stable exertional angina for the past 8 years which particularly became worse in the last 3 months with 5 episodes of nocturnal angina in the preceding month.

The physical examination was unremarkable.

Resting 12 lead ECG showed: (Figures 1-12).
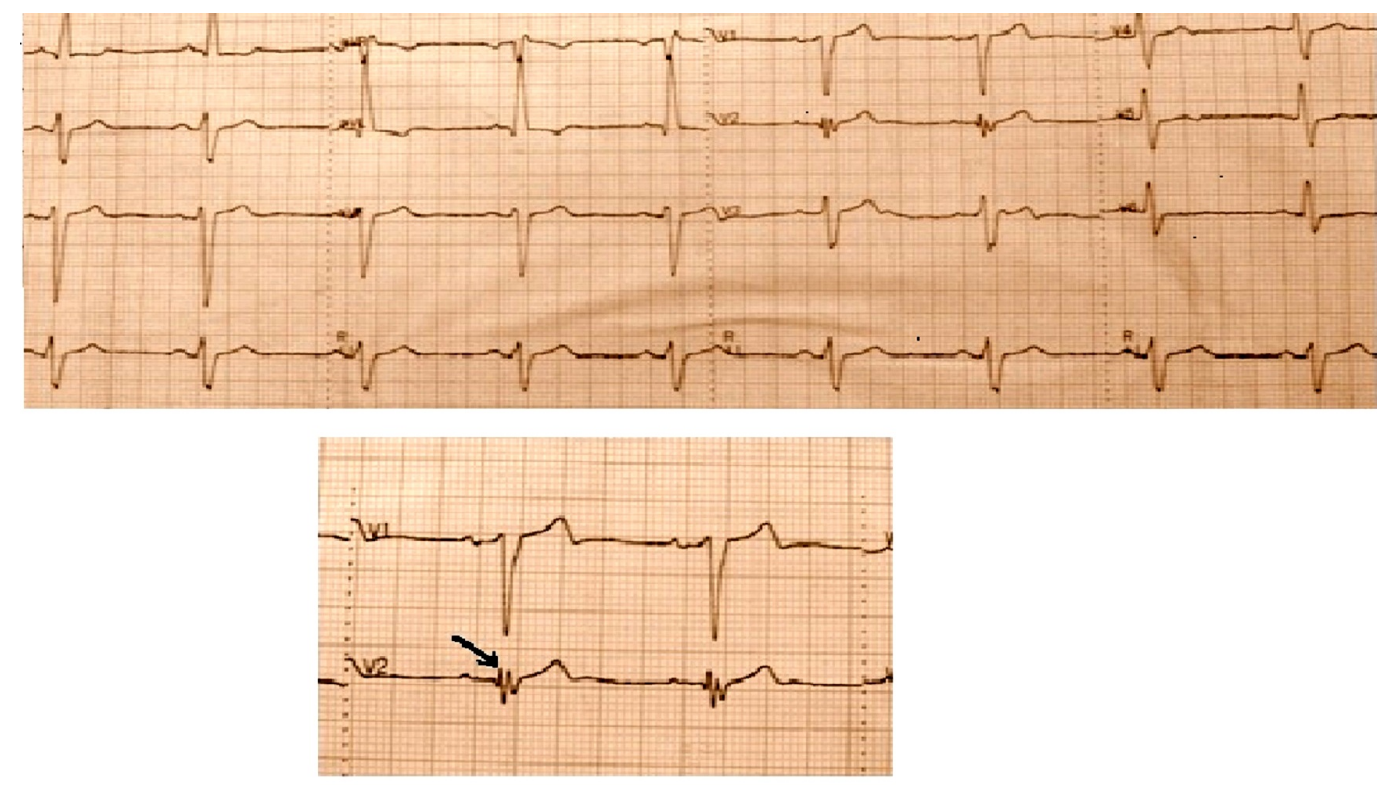

Figure 1. Pre-op ECG with splintered QRS in V2.

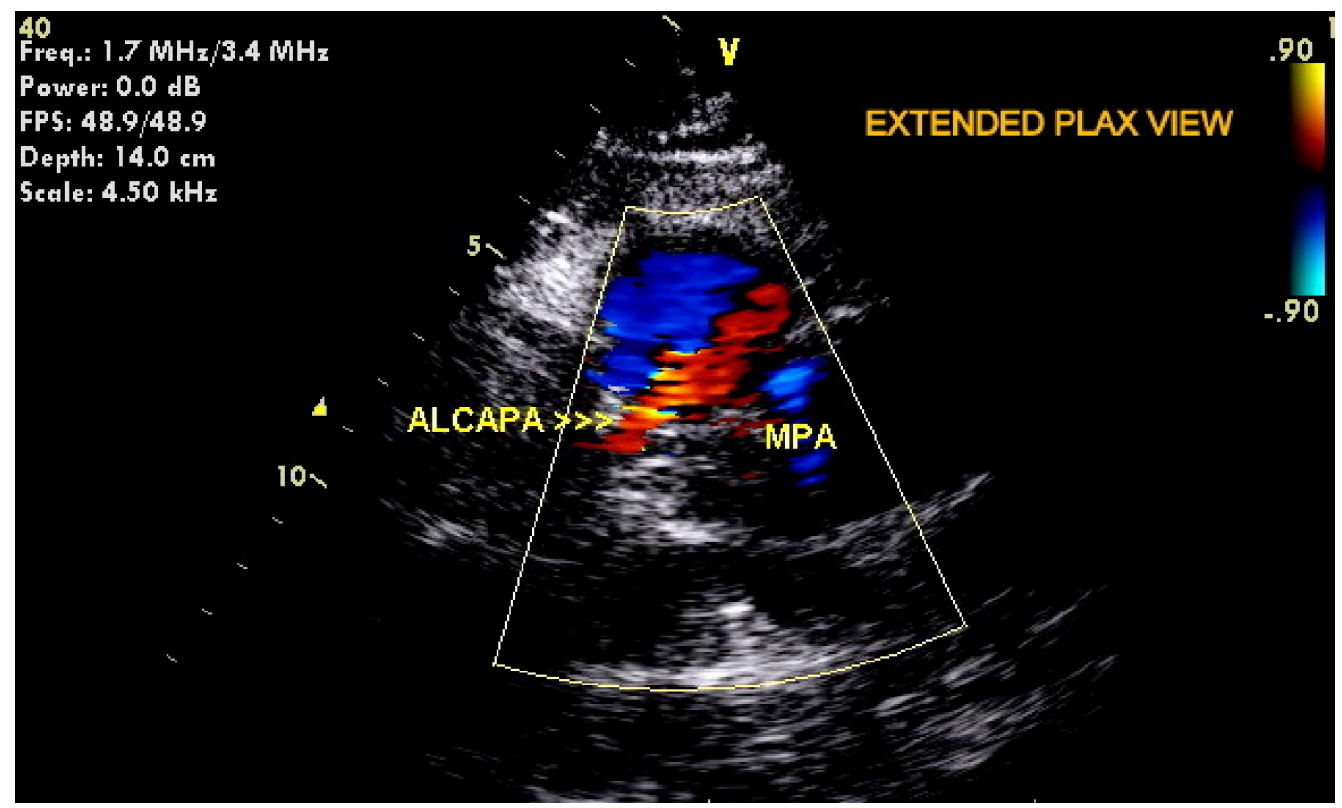

Figure 2. Extended PLAX view with ALCAPA. 


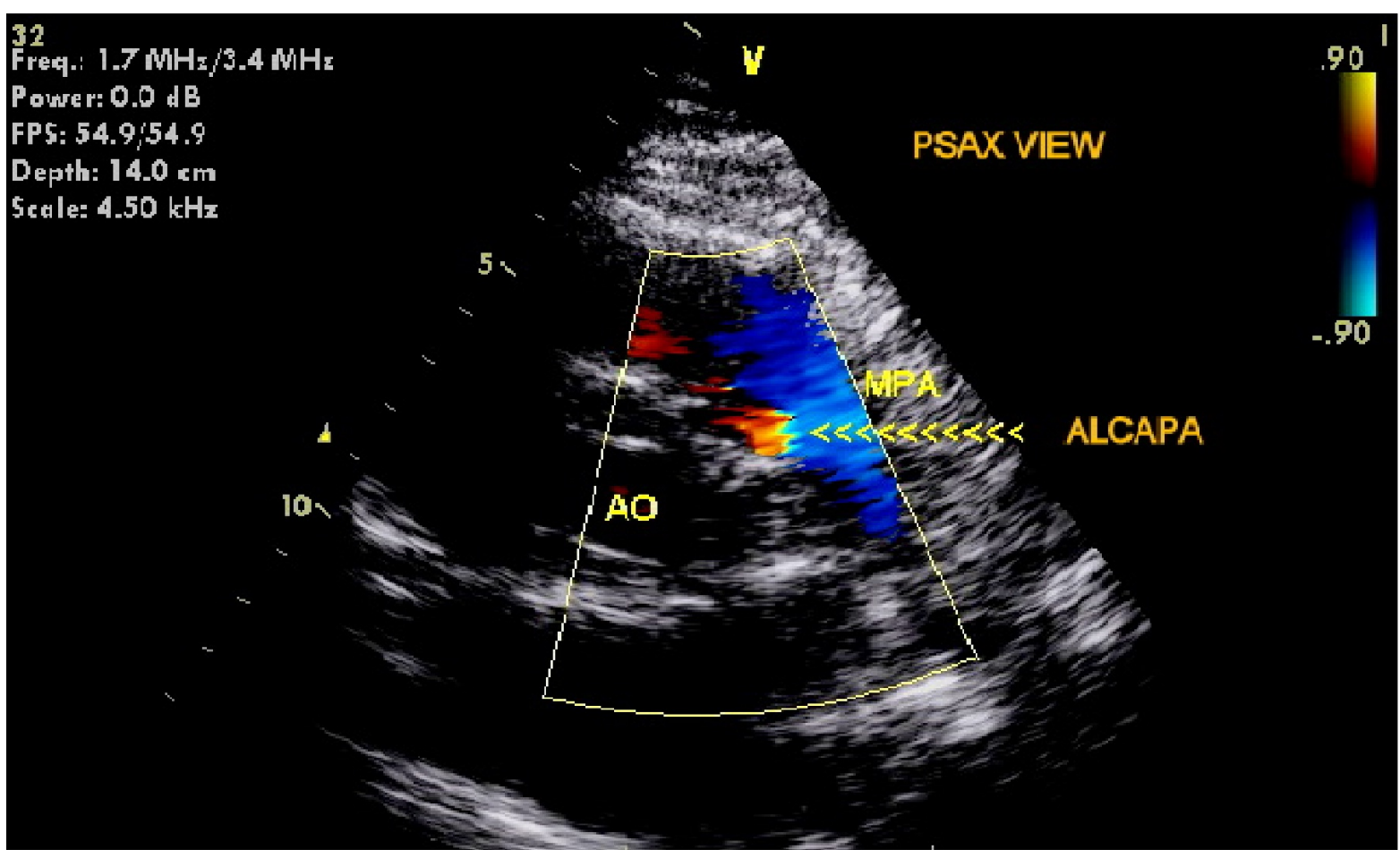

Figure 3. PSAX view with ALCAPA.

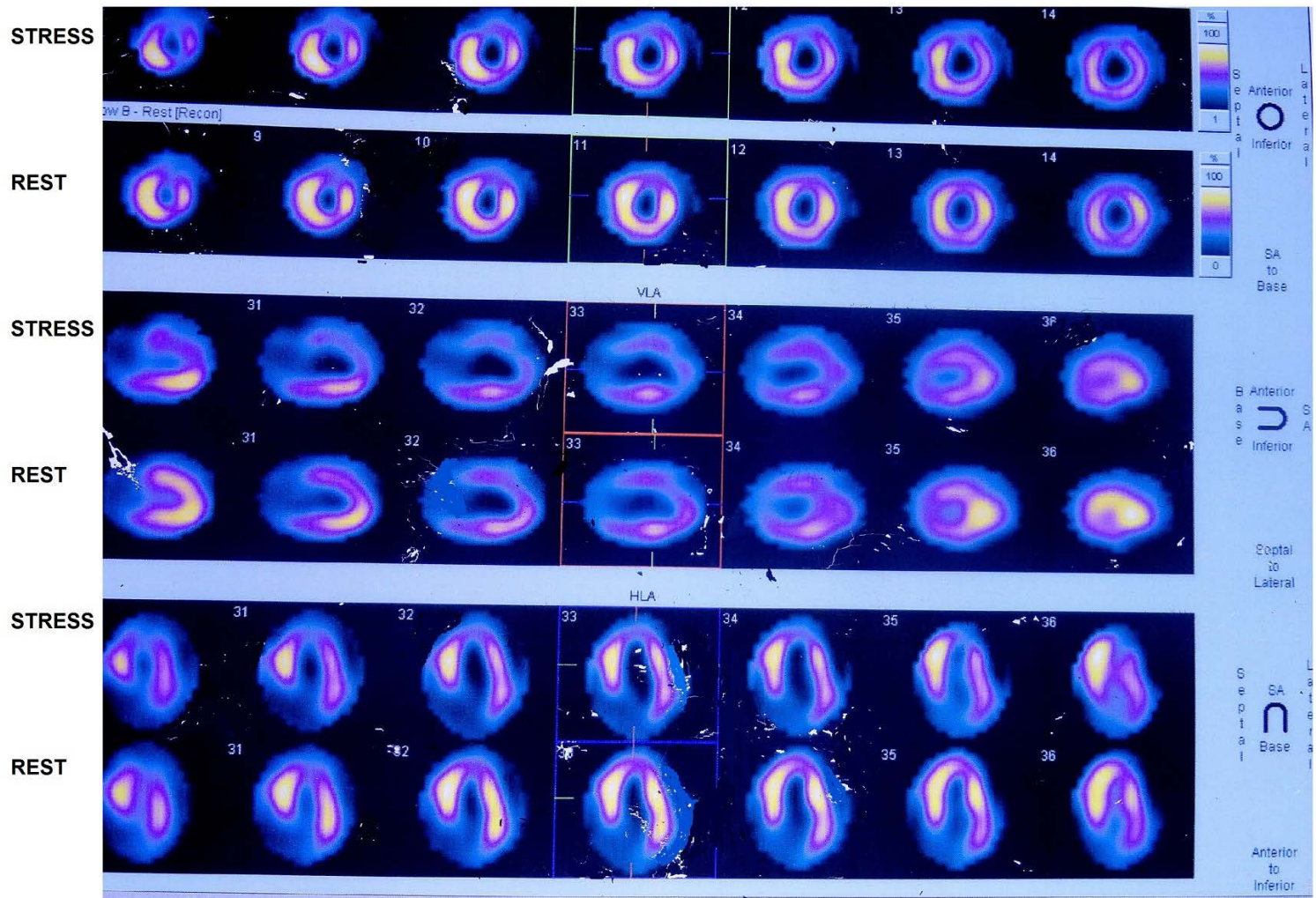

Figure 4. Stress nuclear scan showing reversible perfusion defects in LAD and circumflex territories. 


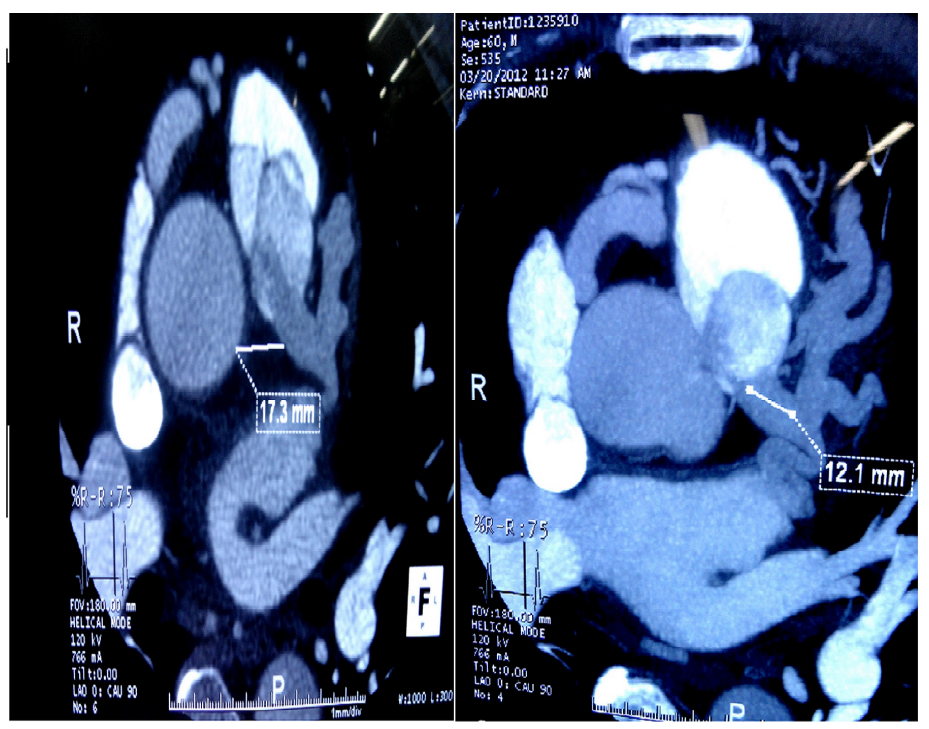

Figure 5. CT Coronary Angiogram demonstrating the LMCA originating from left posterior aspect of MPA, length of LMCA is $12.1 \mathrm{~mm}$ and the distance between MPA and the Aorta $17.3 \mathrm{~mm}$.
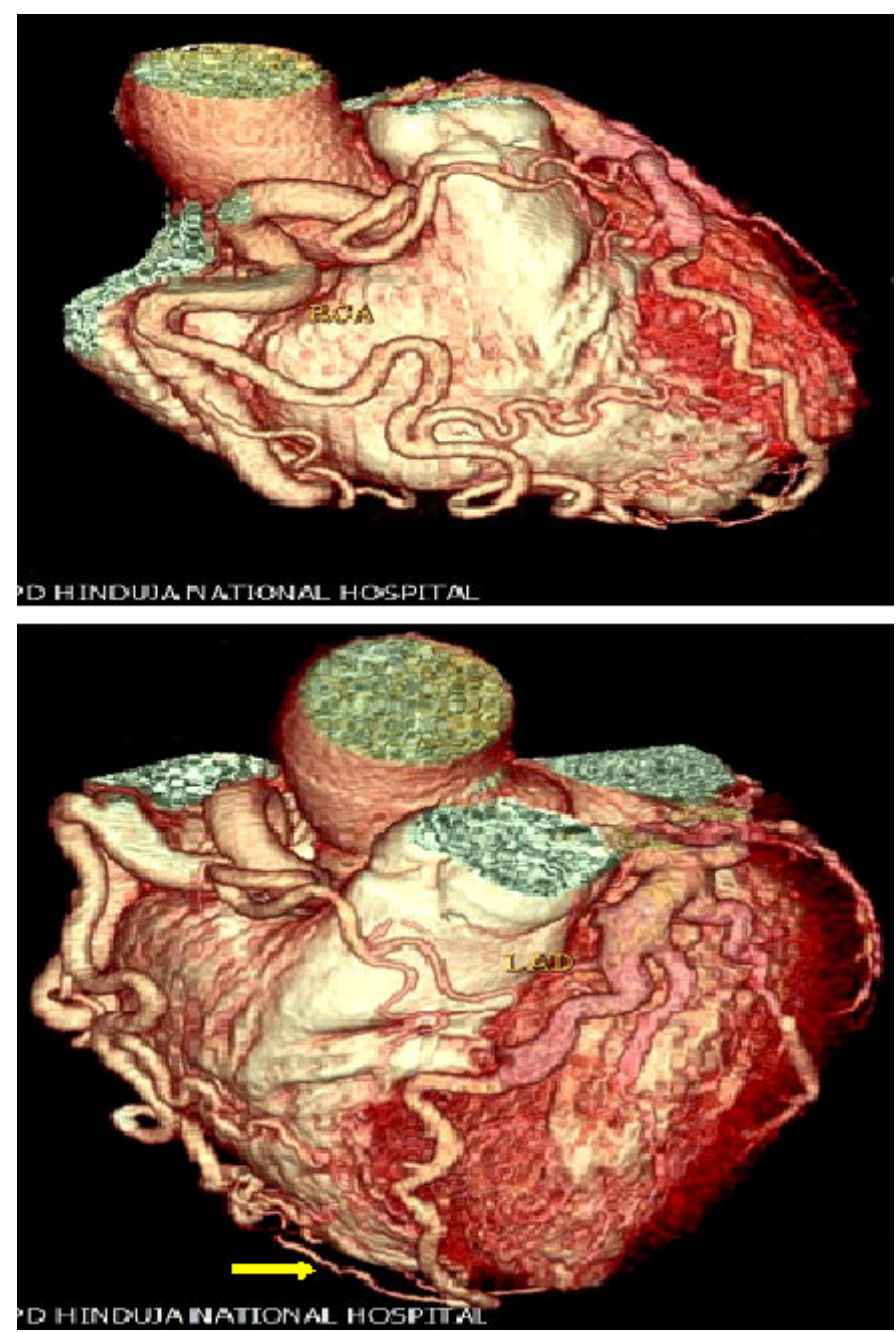

Figure 6. Volumetric CT images showing dilated and tortuous RCA with extensive epicardial collaterals to left system. 


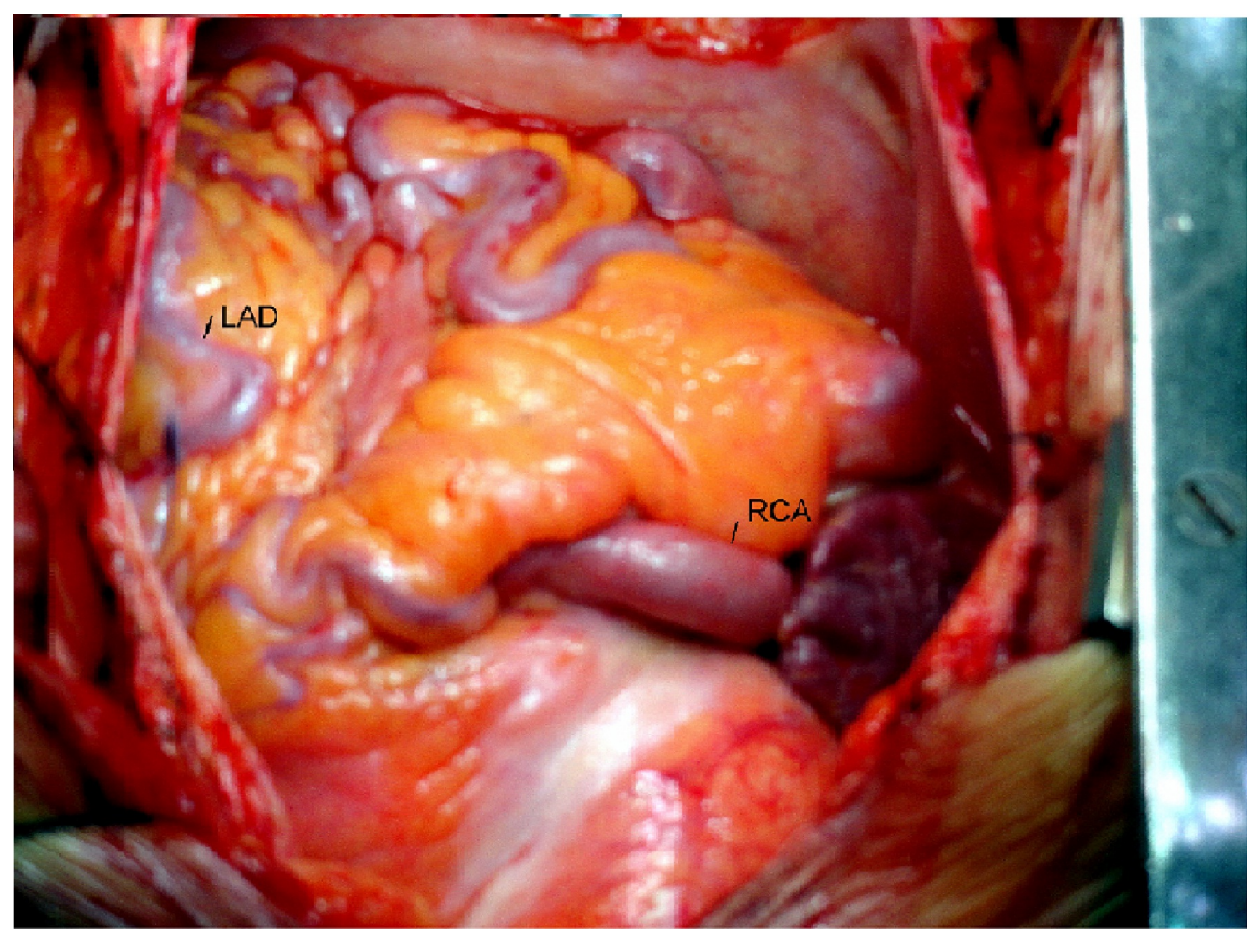

Figure 7. Intra-op off pump heart showing dilated and tortuous RCA with extensive collaterals to the left system.

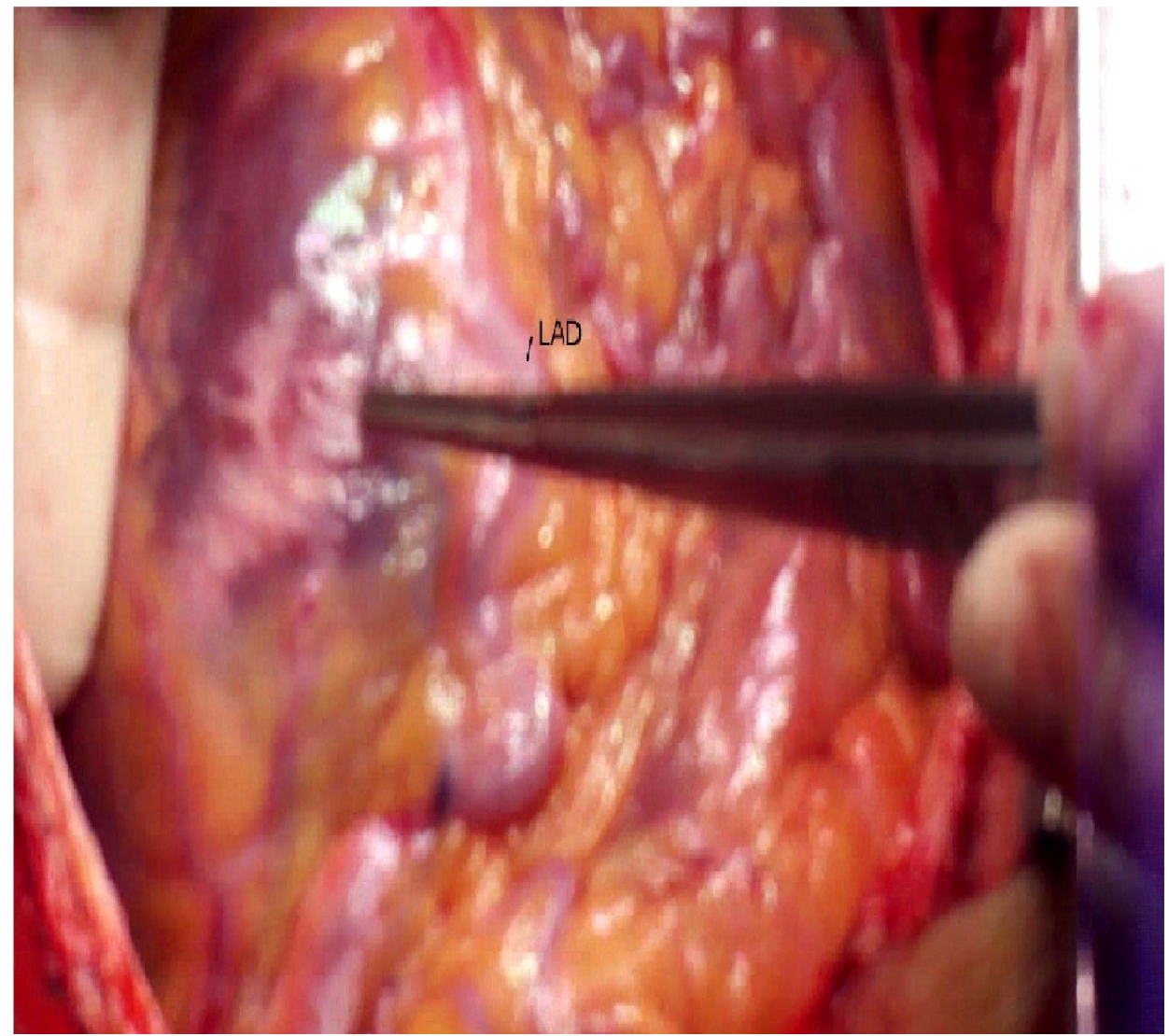

Figure 8. Intra op off pump heart showing scarred tissue in the LAD. 


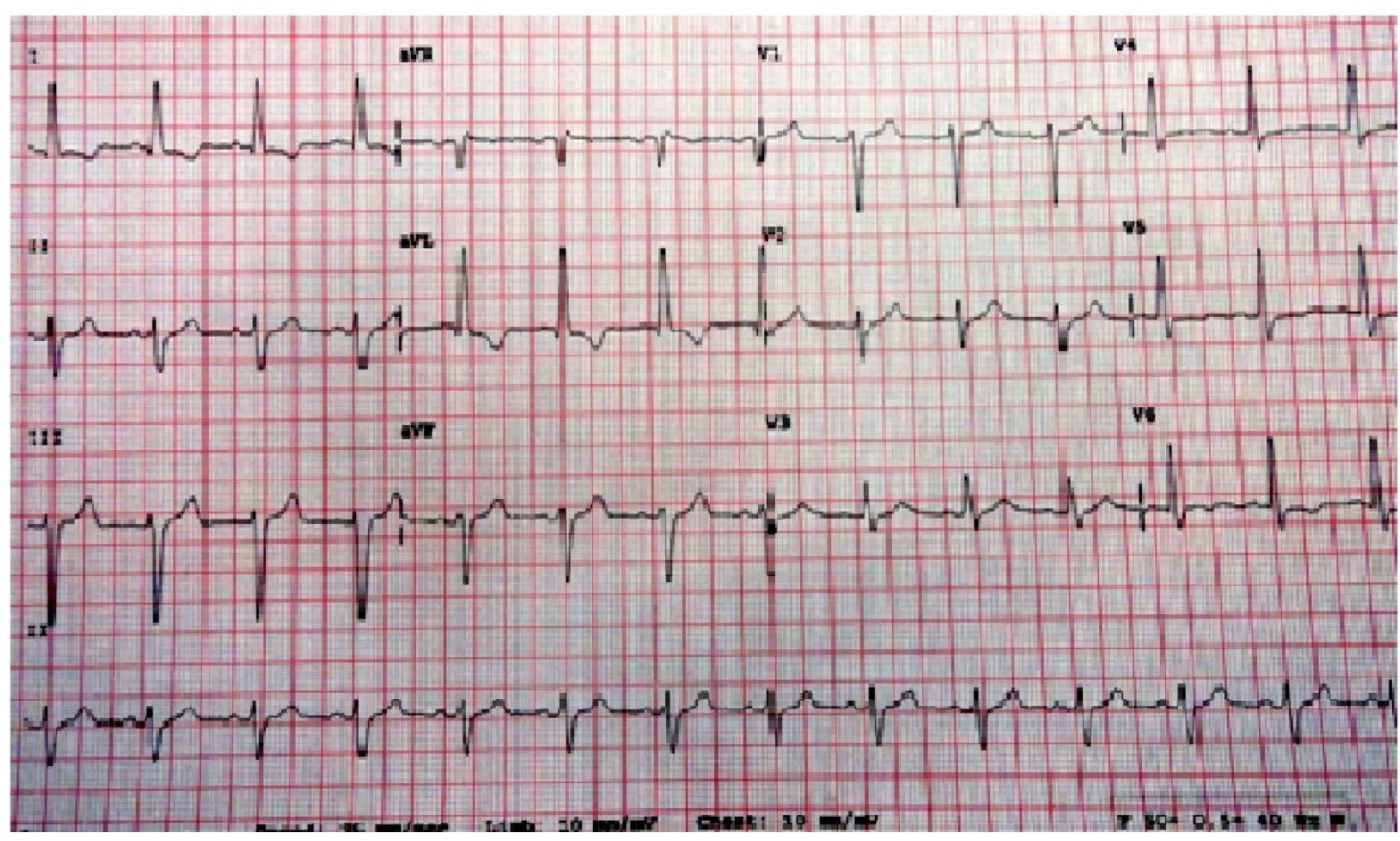

Figure 9. Post op ECG showing narrowed QRS complex and the change in the QRS morphology in V2 as compared to the pre-op ECG.

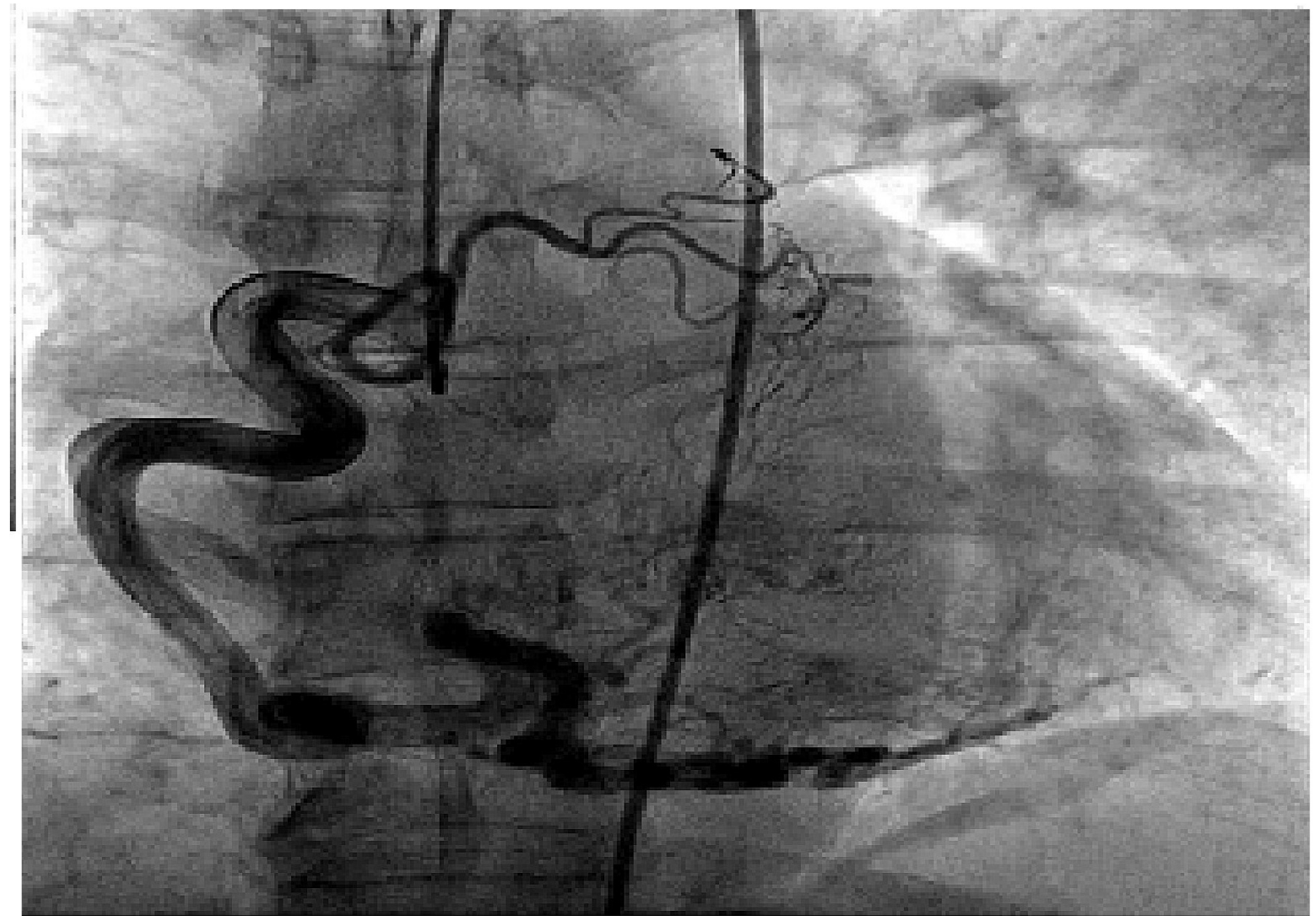

Figure 10. Invasive CAG AP view showing dilated tortuous RCA. 


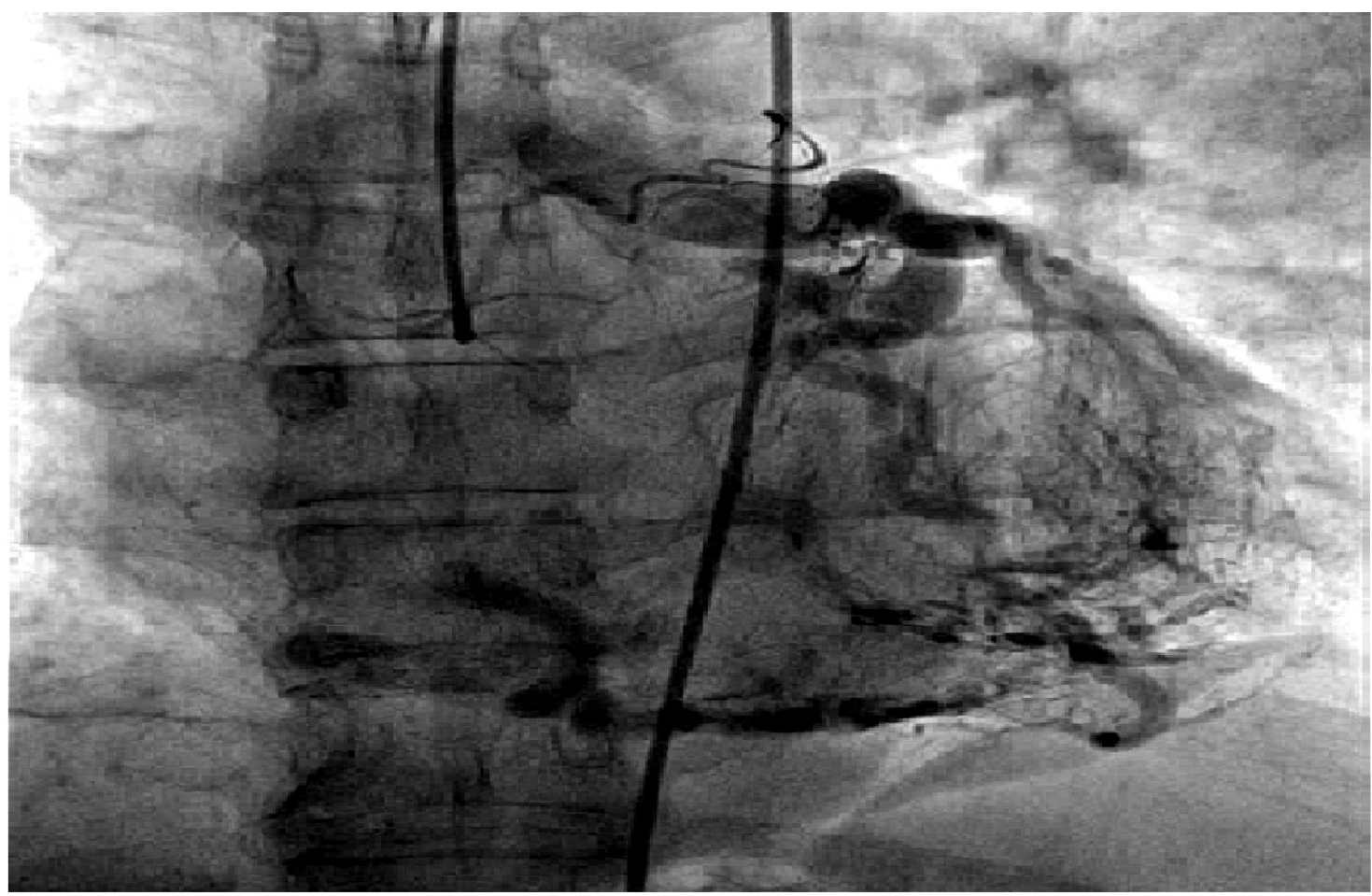

Figure 11. Invasive CAG AP view in the levo phase showing retrograde filling of left system and ALCAPA.

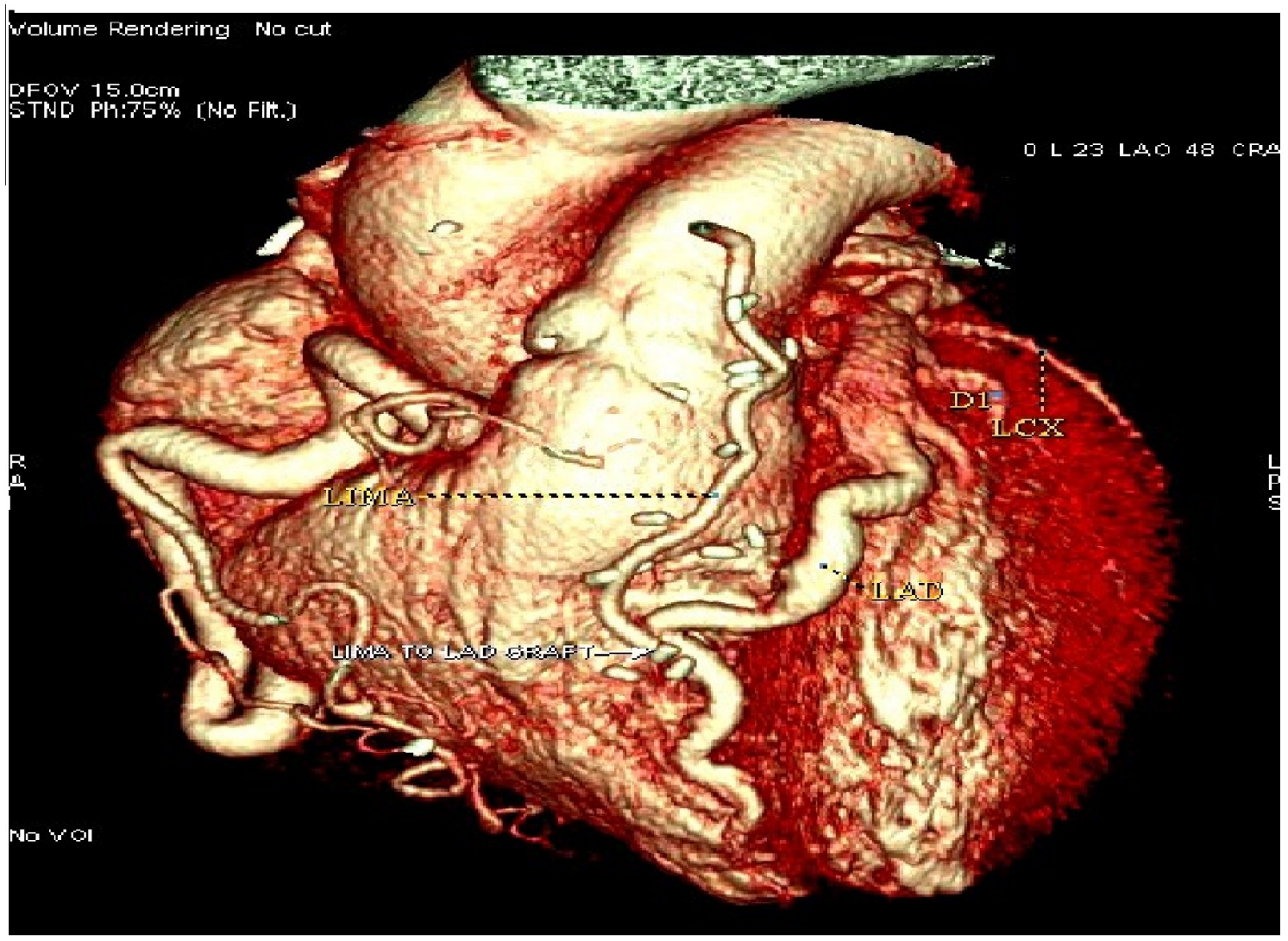

Figure 12. Post operative CT coronary angiogram showing patent. 
- Left anterior hamiblock (LAHB),

- Peculiar splintered QRS in lead "V2" with initial "q" wave.

Patient underwent an invasive coronary angiogram in 2004 which had shown ALCAPA with large tortuous dominant RCA filling the left system.

The 2D Echocardiogram at that time had shown normal global LV systolic function and trace mitral regurgitation.

Patient opted for conservative medical management which he continued for next 7.5 years. In last 3 months his effort tolerance markedly declined to less than quarter of a kilometer on a flat ground.

The repeat 2D Echocardiogram showed mildly dilated LV $(5.4 \mathrm{~cm})$ partial thinning and hypokinesia of apical anterior wall and apical anterior septum with an overall LVEF of $40 \%$.

The extended PLAX view showed a vessel arising from the posterior aspect of main pulmonary artery (MPA) $1 \mathrm{~cm}$ distal to the pulmonary valve with retrograde flow from this vessel into the MPA.

The stress nuclear perfusion scan showed moderately large reversible perfusion defect in LAD and circumflex territories.

A contrast CT coronary angiogram showed a large left main coronary artery $(7 \mathrm{~mm}$ in diameter) originating from the left posterior aspect of main pulmonary artery $1.7 \mathrm{~cm}$ above the level of pulmonary valve and $2.0 \mathrm{~cm}$ away from the closest extent of aortic root (The aorta was "D" posed).

The RCA was markedly enlarged tortuous with big intercoronary collaterals to the entire left system. There were no atherosclerotic lesions either in the RCA or left system.

Intra-operatively the findings of CT coronary angiography were confirmed.

Patient was put on cardiopulmonary bypass pump and it is worthy to notice that even after $600 \mathrm{ml}$ of cold cardioplegia in the aortic root the heart did not arrest and selective cardioplegia into the ostium of anomalous left main coronary artery had to be given after opening the MPA to achieve complete cardioplegia. LIMA was therefore harvested and kept ready in case we find the length of LMCA inappropriate for mobilization.

The length of the left main (LMCA) was only $1.2 \mathrm{~cm}$ and therefore it was not an appropriate length for reimplantation into the aortic root and also the distance between the origin of LMCA and pulmonary valve was barely $1 \mathrm{~cm}$. The surgeon therefore opted to close the LMCA origin from within MPA with an autologous pericardial patch and offered LIMA graft to LAD.

Patient did well with no post operative complication except short lived episode of paralytic ileus.

\section{Discussion}

Most patients with ALCAPA (90\%) die in $1^{\text {st }}$ year of life because of shunting of blood from left coronary system into pulmonary artery leading to severe ischemia in LAD and circumflex territories.

A small percentage of patients surviving until adulthood have extensive collaterals from RCA to left coronary system. Despite the extensive collaterals there occurs coronary steal from the left system into PA leading to chronic left ventricular subendocardial ischemia, progressive left ventricular dysfunction, mitral insufficiency and high incidence of sudden cardiac death [3] [5].

Infants and neonates usually present with heart failure, failure to thrive and rarely can exhibit a continuous murmur at the left base.

Adults on the other hand usually present with effort angina or angina equivalent symptoms.

\section{ECG}

The resting electrocardiogram usually demonstrates pathological "q" waves in leads I, AVL, V5, V6, poor "R" wave progression in precordial leads with sudden shift to qR pattern and infrequently a left axis deviation.

Post-operatively such "q" waves may disappear. In our case, we had a frontal plane QRS axis of $-45^{\circ}$, QRS duration of $120 \mathrm{~ms}$ and a splintered QRS in V2.

In our case postoperatively, QRS narrowed down to $100 \mathrm{~ms}$ and the splintered appearance of QRS in V2 disappeared.

Invasive CAG in adult ALCAPA usually shows dilated tortuous RCA with large intercoronary collaterals supplying the left coronary system. Oximetry may show a small left to right shunt.

In our case, a large super dominant RCA with huge inter coronary collaterals are seen opacifying the left system image (see Figure 1). 
ECG gated ultrafast CT coronary angiography is the modality of choice for the comprehensive evaluation of ALCAPA syndrome and the diagnostic hall marks are:

1) Direct visualization of LMCA from MPA.

2) Dilated tortuous RCA.

3) Dilated multiple inter-coronary collaterals on the epicardial surface of the heart.

4) Dilated bronchial arteries which act as systemic collaterals to LMCA.

The diameter of LMCA, length of LMCA and the distance between LMCA and aorta also can be well assessed by CT angiography and this is valuable information for surgeons.

On 2D-Colour echocardiography the diagnostic hallmark of ALCAPA is the demonstration of LMCA originating from the posterolateral aspect of MPA and the demonstration of a retrograde flow from LMCA to MPA on colour flow imaging.

In our case, we have been able to demonstrate both CT (Figure 5 and Figure 6) and 2D-colour echocardiographic (Figure 2 and Figure 3) findings vividly.

\section{Surgical Repair}

Broadly two types of surgical repairs have been described in literature.

1) One coronary system repair

2) Two coronary system repairs

Single coronary system repair involves simple ligation of anomalous LMCA at its pulmonary origin to avoid the steal. This procedure is now abandoned due to high rate of complications such as severe ischemic MR, recanalization of ALCAPA and high incidence of post-operative sudden death.

Two coronary system repairs are now preferred and are of three following types:

\section{1) Coronary button transfer}

This involves direct re-implantation of LMCA on to the ascending aorta with a button of pulmonary artery

This is mainly practiced in infants and gives best long-term results.

\section{2) Takeushi Procedure}

This involves making a baffle from the MPA wall to tunnel the LMCA through MPA into aorta. Again this is more feasible in infancy.

\section{3) CABG with ligation of anomalous LMCA}

This involves ligation of anomalous LMCA along with venous or arterial bypass grafting of the left coronary system.

In our case, we adapted the third approach as the surgeon felt that the distance between aorta and LMCA is too big for a button transfer. The unique hallmark of our case is the fact that we gave selective cardioplegia into the LMCA after opening the MPA and closed the LMCA opening with pericardial patch on the internal aspect of MPA.

Patient was discharged on dual anti platelet therapy, Carvedilol, statins and Nikorandil. One month post operative CT coronary angiogram showed widely patent LIMA graft to the left system, regression of intercoronary collaterals but the apical portion of the LAD showed presence of small thrombus.

LIMA-> LAD graft

ALCAPA, which though is a rare anomaly with high infantile mortality, can present in adulthood. The treatment of choice is two coronary system repairs, earlier the better. The hallmarks of our case are extraordinarily long survival without $\mathrm{Q}$ wave infarction on ECG and the unique technique of surgical repair.

\section{References}

[1] Brooks, H. (1885) Two Cases of an Abnormal Coronary Artery of the Heart Arising from the Pulmonary Artery: With Some Remarks upon the Effect to This Anomaly in Producing Circoid Dilatation of the Vessels. J Anat Physiol, 20, 26-29.

[2] Pfannschmidt, J., Ruskowski, H. and de Vivie, E.R. (1992) Bland-White-Garland Syndrome. Clinical Aspects, Diagnosis, Therapy. Klinische Pädiatrie, 204, 328-334. (in German) http://dx.doi.org/10.1055/s-2007-1025367

[3] Wesselhoeft, H., Faweett, J.S. and Johsnon, A.L. (1968) Anomalous Origin of the Left Coronary Artery from the Pulmonary Trunk. Its Clinical Spectrum, Pathology, and Pathophysiology, Based on a Review of 140 Cases with Seven Further Cases. Circulation, 38, 403-425. http://dx.doi.org/10.1161/01.CIR.38.2.403 
[4] Alexi-Meskishvili, V., Berger, F., Weng, Y., Lange, P.E. and Hetzer, R. (1995) Anomalous Origin of the Left Coronary Artery from the Pulmonary Artery in Adults. Journal of Cardiac Surgery, 10, 309-315. http://dx.doi.org/10.1111/j.1540-8191.1995.tb00617.x

[5] Bland, E.F. (1933) Congenital Anomalies of the Coronary Arteries: Report of an Unusual Case Associated with Cardiac Hypertrophy. American Heart Journal, 8, 787-801. 
Scientific Research Publishing (SCIRP) is one of the largest Open Access journal publishers. It is currently publishing more than 200 open access, online, peer-reviewed journals covering a wide range of academic disciplines. SCIRP serves the worldwide academic communities and contributes to the progress and application of science with its publication.

Other selected journals from SCIRP are listed as below. Submit your manuscript to us via either submit@scirp.org or Online Submission Portal.
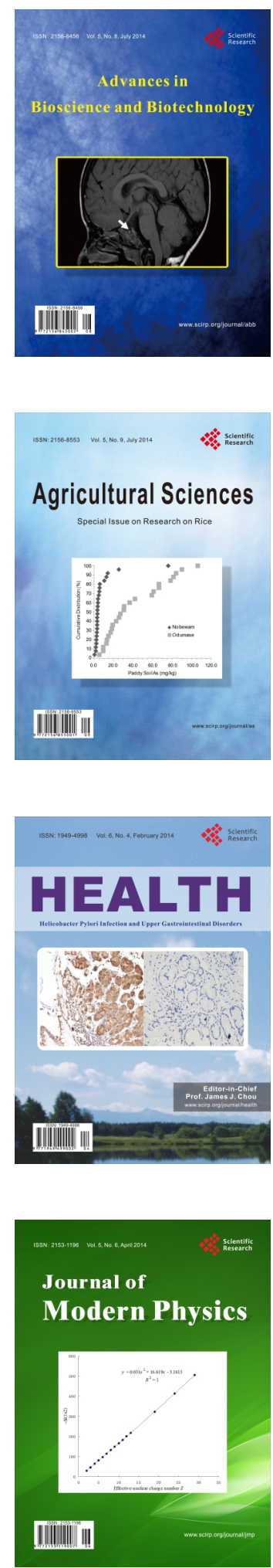
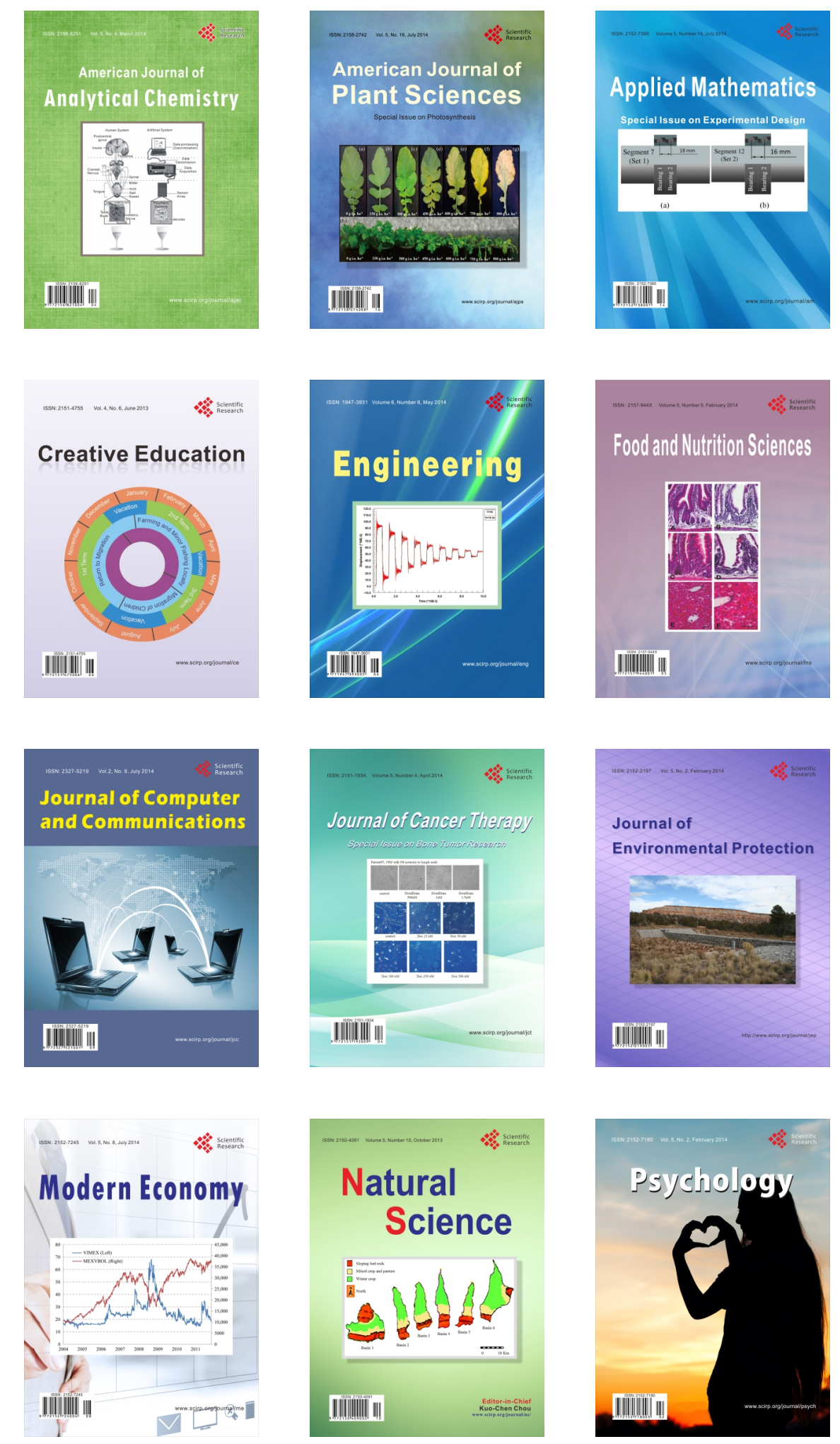